\title{
Uncertain Bequest Needs and Long-Term Insurance Contracts
}

\author{
WENAN FEI \\ Claude Fluet \\ HARRIS SCHLESINGER
}
CESIFO WORKING PAPER No. 2505
CATEgory 3: Social Protection
DECEMBER 2008
An electronic version of the paper may be downloaded
- from the SSRN website:
www.SSRN.com
- from the RePEc website:
- from the CESifo website:
www.RePEc.org
www.CESifo-group.org/wp




\title{
Uncertain Bequest Needs and Long-Term Insurance Contracts
}

\begin{abstract}
We examine how long-term life insurance contracts can be designed to incorporate uncertain future bequest needs. An individual who buys a life insurance contract early in life is often uncertain about the future financial needs of his or her family, in the event of an untimely death. Ideally, the individual would like to insure the risk of having high future bequest needs; but since bequest motives are typically unverifiable, a contract directly insuring these needs is not feasible. We derive two equivalent long-term life insurance contracts that are incentive compatible and achieve a higher welfare level than the naïve strategy of delaying the purchase of insurance until after one's bequest needs are known. We also examine the welfare effects of such contracts and we show how third-party financial products, although beneficial to the individual in the short run, can be welfare decreasing over one's lifetime.
\end{abstract}

JEL Code: D82, D91, G22.

Keywords: asymmetric information, bequest needs, life insurance.

\author{
Wenan Fei \\ Reinsurance Group of America \\ USA - St. Louis \\ wenan_fei@hotmail.com
}

\author{
Claude Fluet \\ Department of Economics \\ University of Quebec at Montreal \\ C.P. 8888, Suc. Centre-Ville \\ Montréal H3C 3P8, Canada \\ fluet.claude-denys@uqam.ca
}

\author{
Harris Schlesinger \\ Department of Finance \\ University of Alabama \\ 200 Alston Hall \\ Tuscaloosa, AL 35487-0224 \\ USA \\ hschlesi@cba.ua.edu
}

November 25, 2008

The authors thank Christophe Courbage, Michael Hoy and Tobias Böhm, as well as participants at the EGRIE meeting in Toulouse and at the CESifo conference on Frontiers in Microceonomic Theory and Policy in Munich for helpful comments on an earlier draft of this paper. 


\section{Introduction}

People purchase life insurance to protect their dependents against financial losses caused by their deaths. In the life insurance market, most contracts extend many years into the future. Such prevalence of long-term contracts is partly due to the premium risk or "insurability risk." In particular, a person's health status may deteriorate, which makes short-term life insurance no longer affordable in the future. In the extreme, a person's health could deteriorate to such an extent that no life insurance is available. A longterm insurance contract with a front-loaded premium schedule, in a certain sense, also provides insurance against this "insurability risk." However, even without such insurability risk, a long-term contract can be beneficial. In particular, we show how such arrangements can improve welfare by partially insuring the risk of having a high bequest demand in the future.

Although it may be advantageous from an insurability standpoint to arrange for life insurance early, the need for life insurance many years later depends on the future demographic structure of the household and may not be known in advance. The impact of one's death often depends on the financial condition of other family members, as well the future preferences of these family members, as examined by Lewis (1989). Moreover, as shown by Bernheim (1991), there is a demand by breadwinners to hold part of their assets in a solely bequeathable form, as opposed a form that could also be used for current consumption if one is alive.

Absent any insurability risk, it would at first appear to be optimal to purchase life insurance contracts later in life, when bequest needs are better known. Another possibility is to purchase short-term contracts and to adjust the insurance level as needed at a later date, as in Polborn et al. (2006). If the status of one's health is private information, this runs into the problem of 
renewability risk. ${ }^{1}$ However, even without the insurability risk, a short-term purchasing strategy for life insurance is not optimal.

Intuitively, although delaying the purchase of life insurance can help individuals to determine the appropriate level of insurance, in concordance with their known bequest demand, one must still pay the extra insurance premium if one's demand turns out to be high. That is, one must plan for the possibility of needing to spend more on insurance premia in the future. Note that this form of "premium risk" has nothing to do with the insurability risk. Here the risk is on the budget required to finance the required amount of life insurance; not on whether or not the premium rate is higher.

In this paper, we consider the design of a long-term life insurance contract that also can help to mitigate the risk of possibly having a high bequest need in the future. Our model is similar to that of Polborn et al. (2006), except that we do not consider the insurability risk. With no insurability risk, but with a risk of demand type, the insurance premium per unit of coverage should not change for short-term contracts. Hence one can always buy more life insurance later at the same price. Polborn et. al. (2006) also mention the case with no insurability risk, but they conclude that there is no benefit to purchasing insurance earlier, since they require zero-profit insurance pricing within each period. ${ }^{2}$

However, a long-term contract can also help to mitigate the risk of bequest type. Although this risk introduces no price risk per se, it does require that individuals with a high-bequest demand spend a higher share of their wealth on life insurance. Thus, a high-bequest demand leads to less consumption

\footnotetext{
${ }^{1}$ See Pauly et al. (1995). However, if this change in insurability is observable, it might be possible, at least in theory, to insure it directly in a manner similar to Cochrane (1995). For commitment problems associated with long-term contracting when changes in insurability are unobservable risk see Hendel and Lizzeri (2003).

${ }^{2}$ Sheshinski (2007) derives similar results in model with annutities, rather than life insurance.
} 
than a low-bequest demand, if an individual does not die early. We show long-term contracts can partially hedge this future consumption risk. This is accomplished by effectively transferring some wealth in future states where one's bequest needs are low to states for which bequest needs are higher. Since bequest needs are not likely to be easily verifiable, the contract cannot just pay a transfer to anyone who claims to have high bequests needs. Hence, the long-term contract is written with particular options, and the exercise of these options occurs via self selection. Long-term contracting also allows for any zero-profit condition to be implemented over the duration of the contract, rather than within each time period.

In the next section, we set up the basic model. We then examine a first-best world in which bequest type is verifiable. We examine the optimal insurance contract, which also provides protection again the risk of having a high bequest need in this setting. Next, we derive two equivalent longterm life insurance contracts for the case where bequest type is unverifiable. These contracts are incentive compatible and achieve a higher welfare level than the naïve strategy of delaying the purchase of insurance until after one's bequest needs are known. These second-best contracts are also compared to the first-best case. We conclude by explaining how some relatively new third party financial products, especially so-called "life settlement" contracts, can upset this long-term contract arrangement.

\section{The Model}

We develop a simple three-period model of life-insurance purchases when individuals are uncertain about their bequest preferences. A person with initial wealth $w_{0}$ at date $t=0$ learns of his preferences for bequest at date $t=1$. The individual faces a probability $q$ of death at date $t=2$. With probability $1-q$, the individual lives to consume another period. To keep 
the model simple and to focus on bequest needs, $q$ is non-random and, thus, there is no insurability risk. For similar reasons, we further assume that the interest rate for borrowing or lending is zero.

Denote by $w^{d}$ and $w^{l}$ the individual's final wealth in the states of death and survival respectively. Let $i$ refer to the individual's type with respect to preferences for bequest at $t=1$. The expected utility of final wealth is then

$$
q v_{i}\left(w^{d}\right)+(1-q) u\left(w^{l}\right),
$$

where $v_{i}\left(w^{d}\right)$ is the utility of leaving wealth $w^{d}$ to dependents at $t=2$ and $u\left(w^{l}\right)$ is the utility of wealth $w^{l}$ in the state of living. Both functions are increasing and strictly concave. Moreover, $v_{i}^{\prime}(w)>u^{\prime}(w)$ for all $w$, implying a demand for life insurance. Taken together, $v_{i}\left(w^{d}\right)$ and $u\left(w^{l}\right)$ can be viewed as a state-dependent value function for the utility derived from the optimal consumption and savings strategies, given the individual's wealth in each state at the beginning of date $t=2$ and taking implicitly into account the future labor income that a surviving individual would earn. ${ }^{3}$

Bequest needs are initially uncertain. At $t=0$, the individual does not know his bequest utility function, which can be either $v_{B}(\cdot)$ with probability $\pi$ or $v_{A}(\cdot)$ with probability $1-\pi$. We assume that $v_{B}^{\prime}(w)>v_{A}^{\prime}(w)$ for all $w$, so that type $B$ is the high-bequest type. An individual's type, once learned, is private information, but insurers know the proportion of types in the population. Any amount of life insurance coverage can be purchased at any time before $t=2$. Let $L$ be the death benefit purchased. ${ }^{4}$ The life

\footnotetext{
${ }^{3}$ In this setting, we can view $w_{0}$ as the present value of lifetime earnings for this person, whom for simplicity we will consider as the sole "bread winner" for the family. If the person dies, then family lifetime income will become less. The state-dependent utility $v$ captures this income loss. Obviously, we are simplifying the basic insurance decision to a great extent. For example, we do not consider that future income might be risky, nor do we consider intermediate consumption. See, for example, Campbell (1980). For a survey of many of these theoretical life insurance issues, see Villeneuve (2000).

${ }^{4}$ We ignore any savings component built into many life insurance contracts. In this
} 
insurance premium is assumed to be actuarially fair, so the premium for the amount of coverage $L$ is $q L$.

As a preliminary step, we examine an individual's demand for life insurance when coverage is purchased at $t=1$, after the individual has learned his type. We then show that, from the perspective of $t=0$, the individual would like to insure against the risk of being a high-bequest type. However, insurance against such a risk cannot be bought directly, since one's type is unverifiable.

\section{Bequest type is verifiable}

Here we consider two insurance strategies. The first is simply to wait until bequest type is known before buying insurance. Even in a world with no insurability risk, the individual has a risk as to how much the total expenditure on insurance will be. In an ideal world, where bequest type is verifiable, this risk can be insured.

\section{The naïve strategy}

The simplest strategy for buying life insurance is to wait until $t=1$ and to purchase coverage after learning one's type. It is useful to characterize the demand for coverage as a function of some arbitrary wealth $w$ at date $t=1$. Obviously, if nothing has been done before this date, then $w=w_{0}$.

For an individual with bequest type $i$ and wealth $w$ at date $t=1$, the life-insurance objective is to

$$
\max _{L_{i}} q v_{i}\left(w-q L_{i}+L_{i}\right)+(1-q) u\left(w-q L_{i}\right), \quad i=A, B
$$

sense, we can regard $L$ as the pure death-protection benefit that is paid in the event of an early death at date $t=2$. More simply, we can view the insurance as a type of term life insurance product that only pays a benefit if death is at date $t=2$. 
The optimal coverage $L_{i}^{*}(w)$ satisfies the first-order condition

$$
v_{i}^{\prime}\left(w-q L_{i}^{*}(w)+L_{i}^{*}(w)\right)-u^{\prime}\left(w-q L_{i}^{*}(w)\right)=0, \quad i=A, B .
$$

Risk aversion ensures that the second-order condition is satisfied. It is easily checked that $L_{B}^{*}(w)>L_{A}^{*}(w)$, i.e., $B$ is indeed the high-bequest type.

Substituting for the optimal amount of coverage yields the date 1 optimal expected utility

$$
V_{i}(w) \equiv q v_{i}\left(w-q L_{i}^{*}(w)+L_{i}^{*}(w)\right)+(1-q) u\left(w-q L_{i}^{*}(w)\right), \quad i=A, B .
$$

Here $V_{i}(w)$ is the value function for a person of type $i$ at date $t=1$, who has wealth $w$ at that date. Viewed from date $t=0$ and treating bequest type as a random variable, $V_{i}(w)$ is a state-dependent utility function exhibiting risk aversion in each state of the world. To see this, apply the envelope theorem and use (1) to obtain

$$
V_{i}^{\prime}(w)=u^{\prime}\left(w-q L_{i}^{*}(w)\right), \quad i=A, B .
$$

Since $L_{B}^{*}(w)>L_{A}^{*}(w)$, it follows that $V_{B}^{\prime}(w)>V_{A}^{\prime}(w)$. Differentiating a second time yields

$$
V_{i}^{\prime \prime}(w)=u^{\prime \prime}\left(w-q L_{i}^{*}(w)\right)\left(1-q L_{i}^{* \prime}(w)\right)<0 .
$$

The sign follows from

$$
1-q L_{i}^{* \prime}(w)=\frac{v_{i}^{\prime \prime}}{(1-q) v_{i}^{\prime \prime}+q u^{\prime \prime}}>0,
$$

where the expression is obtained by total differentiation of (1).

From (3), it is also easily verified that

$$
1-q L_{i}^{* \prime}(w)+L_{i}^{* \prime}(w)=\frac{u^{\prime \prime}}{(1-q) v_{i}^{\prime \prime}+q u^{\prime \prime}}>0 .
$$

Thus, bequest and net wealth in the survival state are normal goods, i.e., $w_{i}^{l} \equiv w-q L_{i}^{*}(w)$ and $w_{i}^{d}=w-q L_{i}^{*}(w)+L_{i}^{*}(w)$ are strictly increasing in the date 1 wealth $w$. 


\section{Insurance against bequest type}

An individual who decides to wait until date $t=1$ to purchase life insurance knows that he will purchase either $L_{A}^{*}\left(w_{0}\right)$ or $L_{B}^{*}\left(w_{0}\right)$, depending on his bequest needs. At date $t=0$, his expected utility is therefore $(1-\pi) V_{A}\left(w_{0}\right)+$ $\pi V_{B}\left(w_{0}\right)$. Since $V_{B}^{\prime}\left(w_{0}\right)>V_{A}^{\prime}\left(w_{0}\right)$, transferring wealth at a fair price from the low to the high marginal utility state increases expected utility. Put differently, the individual would like to insure against the risk of being a high-bequest type.

Suppose for now, contrary to our earlier assumption, that bequest types are verifiable. A contract could then be written at date $t=0$ that pays some amount $Q$ at date $t=1$ if the person turns out to be type $B$. The fair premium for such a contract is $\pi Q$ paid at date $t=0$. The date 1 wealth is now either $w_{A}=w_{0}-\pi Q$ or $w_{B}=w_{0}-\pi Q+Q$ depending on the individual's realized bequest type, where $(1-\pi) w_{A}+\pi w_{B}=w_{0}$.

It is a simple dynamic programming problem to maximize the expectation of the value function

$$
\max _{Q}(1-\pi) V_{A}\left(w_{0}-\pi Q\right)+\pi V_{B}\left(w_{0}-\pi Q+Q\right) .
$$

The optimal $Q^{*}$ satisfies the first-order condition

$$
V_{B}^{\prime}\left(w_{0}-\pi Q^{*}+Q^{*}\right)-V_{A}^{\prime}\left(w_{0}-\pi Q^{*}\right)=0 .
$$

It follows trivially that $Q^{*}>0$, so that $w_{B}^{*}>w_{0}>w_{A}^{*}$.

The life insurance purchased is then $L_{A}^{*}\left(w_{A}^{*}\right)$ if needs are low and $L_{B}^{*}\left(w_{B}^{*}\right)$ if they are high. The possibility of insuring against bequest needs yields a solution characterized by

$$
u^{\prime}\left(w_{A}^{l *}\right)=u^{\prime}\left(w_{B}^{l *}\right)=v_{A}^{\prime}\left(w_{A}^{d *}\right)=v_{B}^{\prime}\left(w_{B}^{d *}\right),
$$

where

$$
w_{i}^{l *}=w_{i}^{*}-q L_{i}^{*}\left(w_{i}^{*}\right), w_{i}^{d *}=w_{i}^{*}-q L_{i}^{*}\left(w_{i}^{*}\right)+L_{i}^{*}\left(w_{i}^{*}\right), \quad i=A, B .
$$


We essentially have a complete contingent claims market and equate marginal utility in all four possible states of the world. This is achieved by combining two types of insurance products: one insures against a premature death and the other insures the uncertain bequest needs. Coverage against the risk of being the high bequest type, equivalently the transfer of wealth from state $A$ to state $B$ individuals is $w_{B}^{*}-w_{A}^{*}=Q^{*}=q\left(L_{B}^{*}\left(w_{B}\right)-L_{A}^{*}\left(w_{A}\right)\right)$, the difference in the life insurance premia. We will refer to this set of contracts as the first-best solution.

\section{Comparison}

It is instructive to compare this first-best solution with the naïve strategy used when preference risks are not insurable. Using the first-best strategy, wealth in the survival state is now equalized across bequest types. Moreover, because of the wealth transfer and since bequests are normal goods, bequests are now larger in the high-bequest state and smaller in the low-bequest state, i.e., $w_{B}^{d *}>w_{0}-q L_{B}^{*}\left(w_{0}\right)+L_{B}^{*}\left(w_{0}\right)$ and $w_{A}^{d *}<w_{0}-q L_{A}^{*}\left(w_{0}\right)+L_{A}^{*}\left(w_{0}\right)$. Thus, the possibility of insuring against preference risks allows the bequest amount to more closely reflect needs.

Figures 1 and 2 provide a state-space representation of the consumer's problem at date $t=1$, when bequest type is known but one's date of death is still uncertain. In figure 1 preference risks are not insured. The negatively sloped straight line is the budget constraint arising from the insurer's zero profit condition, i.e.,

$$
(1-q) w_{i}^{l}+q w_{i}^{d}=w_{0} .
$$

Indifference curves (iso-expected-utility) for both bequest types are shown. For bequest type $i$, the marginal rate of substitution between wealth in the surviving state and wealth in the death state is

$$
-\left(\frac{d w_{i}^{l}}{d w_{i}^{d}}\right)=\frac{q v_{i}^{\prime}\left(w^{d}\right)}{(1-q) u^{\prime}\left(w^{l}\right)} .
$$


For each type, the equilibrium occurs at the tangency point with the budget line, implying $v_{i}^{\prime}\left(w_{i}^{d}\right)=u^{\prime}\left(w_{i}^{l}\right)$. Since type $B$ has steeper indifference curves, $w_{B}^{d}>w_{A}^{d}$ and $w_{B}^{l}<w_{A}^{l}$, leading to equilibria such as the contingent claims $E_{A}$ and $E_{B}$ in figure $1 .^{5}$

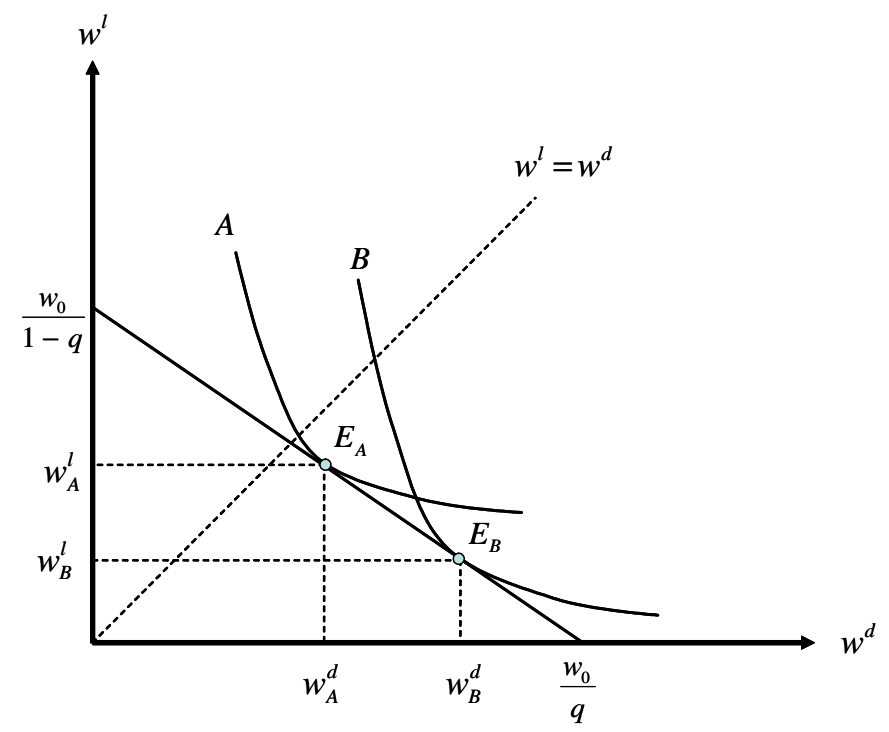

Figue 1: Purchase after type is known

Figure 2 illustrates the case where preference risks can be insured. The date 1 budget constraint is then

$$
(1-q) w_{i}^{l}+q w_{i}^{d}=w_{i}, \quad i=A, B .
$$

The equilibrium contingent claims in this case are $E_{A}^{*}$ and $E_{B}^{*}$ characterized by the condition $w_{B}^{l *}=w_{A}^{l *}$. Moreover, $w_{A}^{d *}$ is smaller and $w_{B}^{d *}$ larger than the corresponding amounts in the uninsured case.

\footnotetext{
${ }^{5}$ See Karni (1985) for a general treatment of models using such state-dependent preferences.
} 


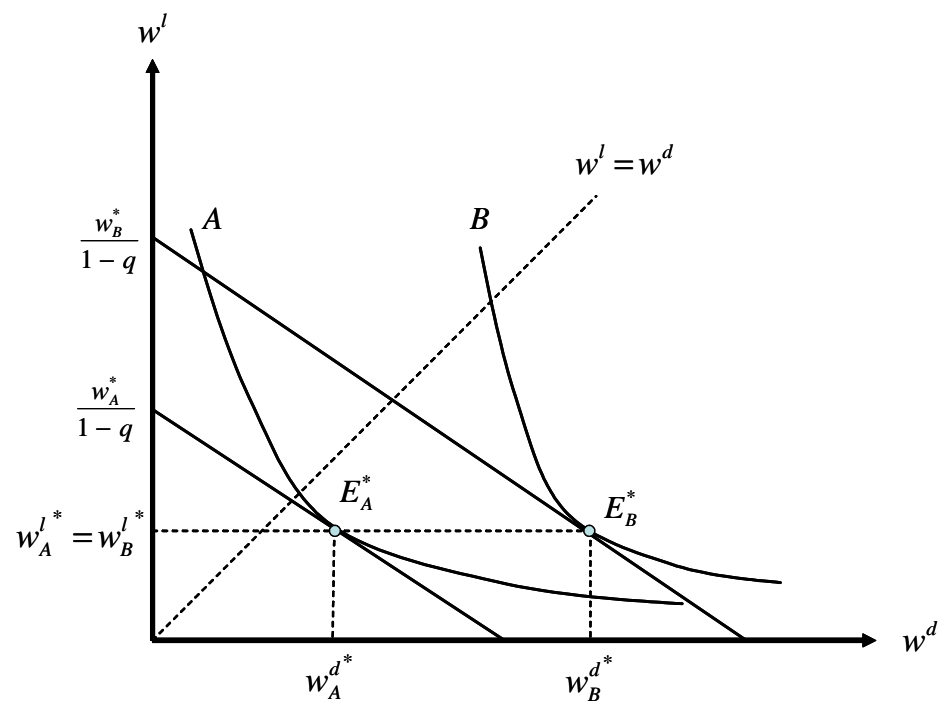

Figure 2: First-best insurance

Of course, direct insurance against bequest type is not feasible if one's bequest type is unverifiable. An individual purchasing such a policy would always want to claim that he is the high bequest type in order to receive the indemnity $Q^{*}$. This is obvious from figure 2. Rather than staying at $E_{A}^{*}$, a type-A individual is better off claiming he is $B$ and moving to the higher budget line.

\section{Bequest type is unverifiable}

We now turn our attention to the case where bequest type is private information and show how we can improve upon the naïve strategy of waiting until date $t=1$ to purchase insurance. Note that it does not matter whether or not type is verifiable by the insurer to implement the naïve strategy.

Long-term life insurance contracts are purchased at date $t=0$, before individuals know their bequest preferences. Many extant life insurance contracts often include provisions that allow for changes to the contract at some 
future date, at the option of the insured. One such type of provision is an opting out opportunity: the insured can trade-in his policy at a later date at some pre-specified buy-back price. Alternatively, the contract can include an option for the purchase of additional coverage at some pre-specified rate. We show that such long-term insurance contracts can improve the individual's welfare even though bequest types are non-verifiable. In particular, a well designed policy allows wealth to effectively be transferred from type-A individuals to type-B individuals.

\section{Opting out contracts}

We consider a contract with a sell back option. We define the contract by the triplet $(P, L, K)$, where $P$ denotes the premium paid at $t=0, L$ denotes the death benefit and $K$ is the price at which the policy can be traded in (i.e. sold back to the insurer) at date $t=1$. With insurers earning zero profit, if only type-A individuals sell back their policies, such a contract will effectively transfer the amount $q L-K$ from type-A individuals to type-B individuals at date $t=1$. In essence, the insurer sells the original coverage $L$ at a subsidized price. The insurer finances this subsidy by buying back the policy at an unfair price from the low-bequest types, who then subsequently purchase a lower level of coverage. ${ }^{6}$

Such an arrangement works if the following three incentive-compatibility conditions are satisfied:

(a) type-A individuals choose to sell back their policy at $t=1$ and buy a

\footnotetext{
${ }^{6}$ As we show below in Proposition 2, the $B$-type contract provides more insurance than would be desirable with just a wealth transfer. Thus, the $B$-types have no desire to purchase more insurance at date $t=1$. Indeed, they would ideally like to purchase less coverage at date $t=0$, but are forced to over-insure in satisfying the constraint (7).
} 
new short-term policy on the "spot" market at actuarially fair prices":

$$
V_{A}\left(w_{0}-P+K\right) \geq q v_{A}\left(w_{0}-P+L\right)+(1-q) u\left(w_{0}-P\right) .
$$

(b) type-B individuals prefer keeping their policy at $t=1$ :

$$
q v_{B}\left(w_{0}-P+L\right)+(1-q) u\left(w_{0}-P\right) \geq V_{B}\left(w_{0}-P+K\right) .
$$

(c) From the perspective of date $t=0$, the arrangement dominates the strategy of waiting until $t=1$ to buy insurance:

$$
U \geq(1-\pi) V_{A}\left(w_{0}\right)+\pi V_{B}\left(w_{0}\right)
$$

where $U$ denotes the expected utility provided by the long-term contract

$$
U \equiv(1-\pi) V_{A}\left(w_{0}-P+K\right)+\pi\left[q v_{B}\left(w_{0}-P+L\right)+(1-q) u\left(w_{0}-P\right)\right]
$$

In addition, the contract must yield a non-negative profit:

$$
P \geq \pi q L+(1-\pi) K
$$

It is easily seen that the set of contracts that satisfy the above constraints is not empty. In particular, consider the contract defined by $L=L_{B}^{*}\left(w_{0}\right)$ and $P=K=q L_{B}^{*}\left(w_{0}\right)$, where $L_{B}^{*}\left(w_{0}\right)$ is the optimal death benefit for type $B$ under the naïve strategy. The non-negative profit condition and (8) are then satisfied as equalities, and (7) is satisfied as a strict inequality. Clearly, this arrangement yields the same outcome as the naïve strategy described in figure 1, implying that (9) is then satisfied as an equality.

In a competitive market, insurers are led to offer the best contract subject to profits being non negative. The equilibrium contract is therefore the one

\footnotetext{
${ }^{7}$ We make the usual assumption that an individual chooses the action designed for him when he is just indifferent between two courses of action.
} 
that maximizes $U$ defined as in (10) subject to the non-negative profit condition and the incentive compatibility conditions. Since it is a maximum, the optimal contract is at least as good as the naïve strategy, i.e., the constraint (9) is trivially satisfied. Also, given $K \leq P$, it is easily checked that (9) implies (8). Thus, the only relevant constraints are (7), which is the opting out condition for type $A$, and the non-negative profit condition (11).

\section{Second-best arrangement}

Under the above arrangement, type $A$ 's wealth at date $t=1$, after exercising his option to sell back his policy, is $w_{A}=w_{0}-P+K$. This type then purchases the optimal death benefit $L_{A}^{*}\left(w_{A}\right)$ in the date 1 market. This yields the final contingent wealth levels $w_{A}^{l}=w_{A}-q L_{A}^{*}\left(w_{A}\right)$ and $w_{A}^{d}=$ $w_{A}-q L_{A}^{*}\left(w_{A}\right)+L_{A}^{*}\left(w_{A}\right)$. Type $B$ does not opt out and thus the final contingent wealth allocation follows directly from the long-term insurance contract, i.e., $w_{B}^{l}=w_{0}-P$ and $w_{B}^{d}=w_{0}-P+L$. The date 1 value of this allocation is

$$
w_{B}=q w_{B}^{d}+(1-q) w_{B}^{l}=w_{0}-P+q L .
$$

The implied wealth transfer from type-A to type-B individuals is therefore $w_{B}-w_{A}=q L-K$.

Written in terms of $w_{A}, w_{B}^{l}$ and $w_{B}^{d}$, the second-best arrangement solves the following program:

$$
\max _{w_{A}, w_{B}^{l} w_{B}^{d}} U=(1-\pi) V_{A}\left(w_{A}\right)+\pi\left[q v_{B}\left(w_{B}^{d}\right)+(1-q) u\left(w_{B}^{l}\right)\right]
$$

subject to

$$
V_{A}\left(w_{A}\right) \geq q v_{A}\left(w_{B}^{d}\right)+(1-q) u\left(w_{B}^{l}\right)
$$

and

$$
(1-\pi) w_{A}+\pi\left[q w_{B}^{d}+(1-q) w_{B}^{l}\right] \leq w_{0}
$$


The first inequality is type $A$ 's incentive compatibility constraint; the second follows from the insurer's non-negative profit condition.

It is straightforward to characterize the main features of the solution to the above problem. The resource constraint (13) is obviously binding. We show first that the self-selection condition (12) must be binding as well. Suppose, to the contrary, that the optimal solution maximizes $U$ subject to (13) only. This is readily seen to yield a solution

$$
V_{A}^{\prime}\left(w_{A}\right)=v_{B}^{\prime}\left(w_{B}^{d}\right)=u^{\prime}\left(w_{B}^{l}\right)
$$

Substituting from (1) and (2), we then have

$$
u^{\prime}\left(w_{A}^{l}\right)=v_{A}^{\prime}\left(w_{A}^{d}\right)=v_{B}^{\prime}\left(w_{B}^{d}\right)=u^{\prime}\left(w_{B}^{l}\right),
$$

which corresponds to the first-best allocation represented in figure 2. However, as is clear from the figure, type $A$ strictly prefers $E_{B}^{*}$ to $E_{A}^{*}$, implying that type $A$ would not opt out, i.e., (12) is not satisfied.

Secondly, the naïve strategy is not a solution. As discussed above, (12) holds as a strict inequality under the naïve strategy. Since this condition must bind, the naïve strategy does not solve the problem. However, since it nevertheless satisfies the constraints, it must be the case be that the individual is strictly better off under the long-term contract. The following proposition summarizes these results.

Proposition 1 Long-term opting-out contracts make individuals strictly better off than the naïve strategy, but they remain second-best compared to the (complete-information) case where bequest needs are directly insurable. 


\section{Levels of coverage}

We next examine how the levels of coverage differ under the various insurance arrangements. The Lagrangian of the second-best program is

$$
\begin{aligned}
& \mathcal{L}=(1-\pi) V_{A}\left(w_{A}\right)+\pi[\left.q v_{B}\left(w_{B}^{d}\right)+(1-q) u\left(w_{B}^{l}\right)\right] \\
&+\mu\left[V_{A}\left(w_{A}\right)-q v_{A}\left(w_{B}^{d}\right)-(1-q) u\left(w_{B}^{l}\right)\right] \\
& \quad+\lambda\left[w_{0}-(1-\pi) w_{A}-\pi\left(q w_{B}^{d}+(1-q) w_{B}^{l}\right)\right],
\end{aligned}
$$

with positive multipliers $\mu$ and $\lambda$. Together with (12) and (13) holding as equalities, the solution satisfies the first-order conditions

$$
\begin{gathered}
\frac{\partial \mathcal{L}}{\partial w_{A}}=(1-\pi+\mu) V_{A}^{\prime}\left(w_{A}\right)-\lambda(1-\pi)=0, \\
\frac{\partial \mathcal{L}}{\partial w_{B}^{d}}=q\left(\pi v_{B}^{\prime}\left(w_{B}^{d}\right)-\mu v_{A}^{\prime}\left(w_{B}^{d}\right)-\lambda \pi\right)=0 \\
\frac{\partial \mathcal{L}}{\partial w_{B}^{l}}=(1-q)\left[(\pi-\mu) u^{\prime}\left(w_{B}^{l}\right)-\lambda \pi\right]=0 .
\end{gathered}
$$

Denote the solution by $\left(\widehat{w}_{A}, \widehat{w}_{B}^{d}, \widehat{w}_{B}^{l}\right)$. The date-1 value of type $B$ 's allocation is $\widehat{w}_{B} \equiv q \widehat{w}_{B}^{d}+(1-q) \widehat{w}_{B}^{l}$. Type $A$ 's allocation is $\widehat{w}_{A}^{d}$ and $\widehat{w}_{A}^{l}$ satisfying

$$
v_{A}^{\prime}\left(\widehat{w}_{A}^{d}\right)=u^{\prime}\left(\widehat{w}_{A}^{l}\right)=V_{A}^{\prime}\left(\widehat{w}_{A}\right)
$$

An illustration is given in figure 3. We derive two results. First, the wealth transfer from type-A to type-B individuals in the long-term arrangement is smaller than in the first-best contract. Secondly, the second-best contract provides a greater death benefit than type $B$ would wish if he could purchase freely on the basis of his contractually defined date 1 wealth. 


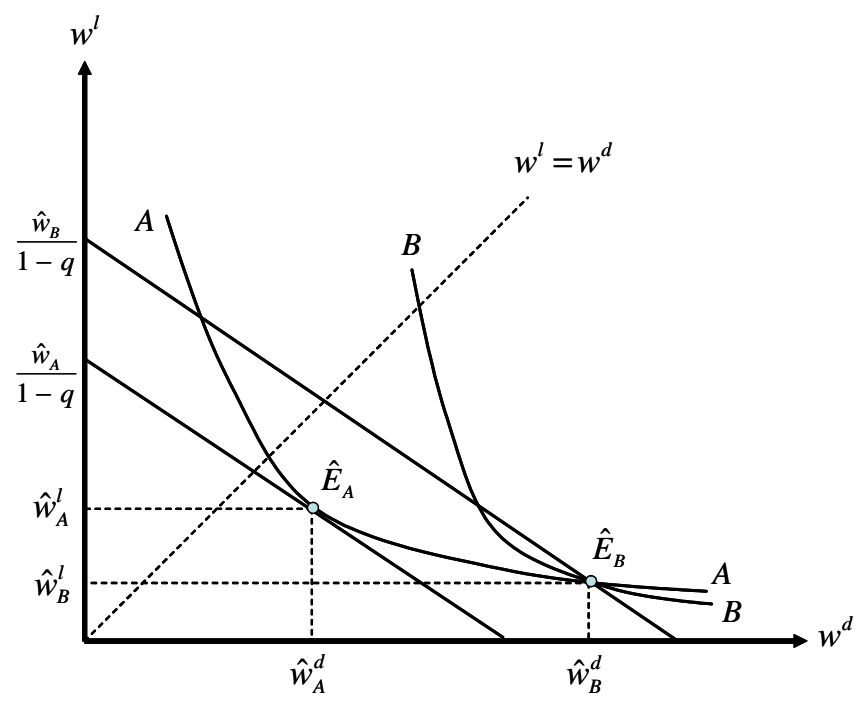

Figure 3: Second-best long term contracts

Wealth transfer. We show that the subsidy from type- $A$ to type- $B$ individuals is lower in the second-best solution vis-à-vis the first-best one: $\widehat{w}_{B}-\widehat{w}_{A}<w_{B}^{*}-w_{A}^{*}$. Suppose, to the contrary, that

$$
\widehat{w}_{B}-\widehat{w}_{A} \geq w_{B}^{*}-w_{A}^{*}
$$

From the zero-profit condition, the state wealth levels satisfy

$$
(1-\pi) \widehat{w}_{A}+\pi \widehat{w}_{B}=(1-\pi) w_{A}^{*}+\pi w_{B}^{*}=w_{0} .
$$

Hence, (18) implies $\widehat{w}_{A} \leq w_{A}^{*}$ and $\widehat{w}_{B} \geq w_{B}^{*}$. A's date-1 budget line in the second-best arrangement is then below the first-best one represented in figure 2 , while $B$ 's budget line is above the one in figure 2 .

$A$ 's allocation satisfies (17). Since bequest and survival wealth are normal goods, (18) therefore implies $\widehat{w}_{A}^{l} \leq w_{A}^{l *}$ and $\widehat{w}_{A}^{d} \leq w_{A}^{d *}$. Consider now $B$ 's allocation. This is given by the intersection of $A$ 's indifference curve through $\left(\widehat{w}_{A}^{d}, \widehat{w}_{A}^{l}\right)$ and $B$ 's budget line. Obviously, the foregoing implies $\widehat{w}_{B}^{d}>w_{B}^{d *}$. Combining both these results yields

$$
v_{A}^{\prime}\left(\widehat{w}_{A}^{d}\right) \geq v_{A}^{\prime}\left(w_{A}^{d *}\right)=v_{B}^{\prime}\left(w_{B}^{d *}\right)>v_{B}^{\prime}\left(\widehat{w}_{B}^{d}\right),
$$


where the equality follows from the optimality conditions for a first best.

We now turn to the restrictions imposed by the first-order conditions. From (14) and (15) it follows that

$$
v_{B}^{\prime}\left(\widehat{w}_{B}^{d}\right)=\left(\frac{1-\pi+\mu}{1-\pi}\right) V_{A}^{\prime}\left(\widehat{w}_{A}\right)+\left(\frac{\mu}{\pi}\right) v_{A}^{\prime}\left(\widehat{w}_{B}^{d}\right) .
$$

Substituting for $V_{A}^{\prime}\left(\widehat{w}_{A}\right)=v_{A}^{\prime}\left(\widehat{w}_{A}^{d}\right)$ from (17), (20) implies $v_{B}^{\prime}\left(\widehat{w}_{B}^{d}\right)>v_{A}^{\prime}\left(\widehat{w}_{A}^{d}\right)$ which contradicts (19). The wealth transfer must therefore be strictly smaller in the second-best arrangement.

Distortion. Here we show that the $B$-type is forced to "overinsure," which can be interpreted as a type of signalling cost in the second-best setting. This distortion is represented by a point such as $\widehat{E}_{B}$ in figure 3 . As drawn, the long-term contract provides a larger bequest (and correspondingly smaller survival wealth) than type $B$ would wish to purchase voluntarily on the basis of the post-transfer wealth level $\widehat{w}_{B}$. In other words, $L>L_{B}^{*}\left(\widehat{w}_{B}\right)$ or equivalently $\widehat{w}_{B}^{d}>\widehat{w}_{B}-q L_{B}^{*}\left(\widehat{w}_{B}\right)+L_{B}^{*}\left(\widehat{w}_{B}\right)$. This is a necessary feature of the second-best arrangement. The intuition is that this "distortion" facilitates the transfer of wealth from state $A$ to state $B$, by making it more costly for type $A$ not to opt out of the initial contract.

To see this more formally, substituting from (15) and (16) yields

$$
v_{B}^{\prime}\left(\widehat{w}_{B}^{d}\right)-u^{\prime}\left(\widehat{w}_{B}^{l}\right)=\frac{\mu}{\pi}\left(v_{A}^{\prime}\left(\widehat{w}_{B}^{d}\right)-u^{\prime}\left(\widehat{w}_{B}^{l}\right)\right) .
$$

No "distortion" would require that the left-hand side is zero, which in turn implies $v_{A}^{\prime}\left(\widehat{w}_{B}^{d}\right)=v_{B}^{\prime}\left(\widehat{w}_{B}^{d}\right)$, a contradiction. Moreover, $B$ 's indifference curve through $\widehat{E}_{B}$ cannot be steeper than the fair-odds line. Otherwise, a pair $\left(w_{B}^{d}, w_{B}^{l}\right)$ could be chosen on the same fair-odds line below $A$ 's indifference curve through $\widehat{E}_{B}$ that satisfies $A$ 's incentive compatibility constraint and is strictly preferred by $B$. Hence, we must have $L$ larger than $L_{B}^{*}\left(\widehat{w}_{B}\right)$ as claimed.

The next proposition summarizes our results. 
Proposition 2 Under the second-best long-term contract

(i) the wealth transfer between type $A$ and type $B$ is smaller than the first-best transfer and

(ii) high-bequest types are over-insured relative to the coverage they would like to have at the contractually defined wealth level.

The foregoing results imply that type- $A$ 's bequest and survival wealth are greater than in the first best, while type- $B$ 's survival wealth is smaller. However, how type- $B$ 's bequest compares with the first-best level is ambiguous. There are two opposing effects so to speak. On the hand, because of the distortion, $B$ 's equilibrium bequest is larger than he would wish at the wealth level $\widehat{w}_{B}$. On the other hand, his wealth level is lower than the first-best $w_{B}^{*}$. When conditional wealth levels do not differ too much from the first best, it may therefore be that $B$ leaves a larger bequest. In this case, bequest by both types are greater than in the first best.

It is interesting to note that at date 1 , an individual who turns out to be type $A$ will be better off with the second-best contract than with the first-best one. This is to be expected, since the subsidy is lower under the secondbest arrangement. In other words, at date 0 the individual would prefer the extra protection afforded by a larger subsidy. However, an individual who eventually turns out to be of a low-bequest type will be happier if the subsidy is smaller when date 1 arrives. $^{8}$

\section{Opting in contracts}

An alternative to the opting out arrangement is to offer a contract with an option to purchase additional coverage at date $t=1$. Such an "opt-in" contract is defined by the vector $(\bar{P}, \bar{L}, S, k)$ where $\bar{P}$ is the premium paid at $t=0$ for coverage $\bar{L}$ and $S$ is the optional additional coverage that the

\footnotetext{
${ }^{8}$ This is an often overlooked artifact of most adverse-selection models.
} 
individual can purchase at date $t=1$ for an additional premium $k$. If $\bar{P}>q \bar{L}$ and $k<q S$, then wealth will be transferred from type- $A$ individuals to type- $B$ individuals, provided of course only type $B$ exercises the option to purchase additional coverage. Here, the original coverage $\bar{L}$ is sold at an unfair premium. The non-negative profit constraint under this opting-in arrangement is

$$
\bar{P} \geq q \bar{L}+\pi(q S-k) .
$$

The above contract is equivalent to selling both types an initial contract with death benefit $(\bar{L}+S)$ for a premium of $(\bar{P}+k)$. The type- $B$ individual "opts in" by maintaining this package at date $t=1$. The type- $A$ individual refuses to "opt in" at date $t=1$ by obtaining a refund of the extra premium $k$, and reducing the death total benefit by an amount $S .{ }^{9}$ As before, effectively only the $A$-type's incentive compatibility constraint matters, with the type- $A$ individual being just indifferent between opting in or not opting in.

Defining

$$
P \equiv \bar{P}+k, \quad L \equiv \bar{L}+S \quad \text { and } K \equiv q \bar{L}+k,
$$

it is easily seen that the non-negative profit constraint (21) is equivalent to the previous non-negative profit constraint (11), and it will be satisfied once again with an equality at the optimum. We have one additional requirement here, namely that a type- $A$ individual who would receive a refund $q \bar{L}+k$ at date $t=$ 1 would purchase an optimal level of insurance coverage $L_{A}^{*}\left(w_{0}-\bar{P}+q \bar{L}\right)=\bar{L}$, if insurance would be available at a fair price. More formally, from the firstorder condition for $L_{A}^{*}$, this requires that

$$
v_{A}^{\prime}\left(w_{0}-\bar{P}+q \bar{L}-q L_{A}^{*}+L_{A}^{*}\right)=u^{\prime}\left(w_{0}-\bar{P}+q \bar{L}-q L_{A}^{*}\right)
$$

\footnotetext{
${ }^{9}$ These opting in contracts have the property that the premium loading is collected in the first period, which is similar to the types of contracts that one observes for renewable insurance contracts when there is an insurability risk. Of course, the design in those models is for quite a different purpose; namely, to cope with asymmetry about one's risk type.
} 
be satisfied when $L_{A}^{*}\left(w_{0}-\bar{P}+q \bar{L}\right)=\bar{L}$.

It then follows in a straightforward manner that the same triple $(P, L, K)$ is optimal, which together with (22) and (23) determine the parameters for the optimal opt-in contract: $(\bar{P}, \bar{L}, S, k)$. Thus, the opting-in and opting-out arrangements are effectively identical. ${ }^{10}$

\section{Concluding Remarks}

This paper has shown how a long-term insurance contract can be designed, within a competitive insurance market, to insure the uncertain future bequest needs of the individual. We derived two equivalent forms for this long-term insurance contract: ${ }^{11}$

(i) It provides a high level of initial coverage at a subsidized (low) price, with an option to sell back the policy at an unfair price (i.e. at a loss to the insured)

or

(ii) It provides a low level of initial coverage at an unfair (high) price, with an option to purchase additional coverage at a subsidized (low) price.

The existence of such contracts in the market place depends crucially on the self selection of types in exercising the various options. But some relatively new innovations in the financial marketplace may have an untoward effect on the development of the long-term contracts we propose. In particular, the market for life settlements poses such an obstacle.

\footnotetext{
${ }^{10}$ One can also verify this directly by writing out the incentive compatibility constraints and then finding the optimal $(\bar{P}, \bar{L}, S, k)$ directly, which together with (23) shows the equivalence of the two types of contract arrangements.

${ }^{11}$ These two forms will not be unique. For example, an intermediate level of insurance could be offered with both "opt in" and "opt out" opportunities to achieve the same final wealth levels.
} 
A life settlement contract essentially offers to "buy back" the life insurance policy of an individual. This is effected via a third party paying cash to the insured, in exchange for being named the beneficiary of the life insurance death benefit. Although this seems to eliminate any benefit to the original beneficiary, this will not be the case. In particular, under contract $(i)$, the low-bequest need individual will opt to sell the policy to a life settlement broker, rather than back to the insurer, and receive more money for the policy. The insured can then purchase insurance at a fair price, since there is no insurability risk. Under contract (ii), both bequest types might purchase the additional extra insurance at the low price, with the low-bequest need type individual then immediately selling back the extra coverage in the life settlement market for a profit.

The existence of such markets provides an alternative for the insured that is beneficial ex post (i.e., after signing the original long-term contract). Insurance companies had originally protested as these markets developed, claiming that they should have the exclusive right to buy-back (i.e. "settle") contracts that they had written. But others disagree. For example, Doherty and Singer (2002) tout the benefits of life settlement markets to the insurance consumer. Such analysis might be incomplete, however, in that it excludes the fact that ex ante (i.e. prior to learning one's bequest type) one would prefer the longer term contracts described in this paper; and the life settlement market might preclude such contracts from ever being offered. Although the long-term contracts we describe in this paper give the insurer monopoly power ex post, a competitive market ex ante should ensure that insurers cannot earn undue monopoly rents.

Obviously, we simplified the setting of our analysis by assuming away many complicating factors, such as the insurability risk. This allowed our focus to be on the bequest needs and the (non-random) probability of death. Integrating these results into more complex settings is difficult. Hopefully, 
our paper takes a good first step in this direction.

\section{References}

[1] Bernheim, D. A. (1991). How strong are bequest motives? Evidence based on estimates of the demand for life insurance and annuities. Journal of Political Economy 99, 899-927.

[2] Campbell, R. A. (1980). Demand for life insurance: An application of the economics of uncertainty. Journal of Finance 35, 1155-1172.

[3] Cochrane, J. H. (1995). Time-consistent health insurance. Journal of Political Economy 103, 447-473.

[4] Doherty, N. A. and Singer, H. J. (2002). The benefit of a secondary market for life insurance policies, Wharton Financial Institutions Center Working Paper No. 02-41.

[5] Hendel, I. and Lizzeri, A. (2003). The role of commitment in dynamic contracts: Evidence from life insurance. Quarterly Journal of Economics 118, 299-327.

[6] Karni, E., (1985). Decision Making Under Uncertainty: The Case of State-Dependent Utility. Cambridge, MA: Harvard University Press.

[7] Lewis, F. D. (1989). Dependents and the demand for life insurance. American Economic Review 79, 452-467.

[8] Pauly, M. V.; Kunreuther, H.; and Hirth, R. (1995). Guaranteed renewability in insurance. Journal of Risk and Uncertainty 10, 143-156.

[9] Polborn, M. K., Hoy, M., \& Sadanand, A. (2006). Advantageous effects of regulatory adverse selection in the life insurance market. Economic Journal 116, 327-354. 
[10] Sheshinski, E. (2007). Optimum and risk-class pricing of annuities. Economic Journal 117, 240-251.

[11] Villeneuve, B. (2000). Life insurance, in: G. Dionne, Editor, Handbook of Insurance, Boston: Kluwer Academic Publishers. 


\section{CESifo Working Paper Series}

for full list see www.cesifo-group.org/wp

(address: Poschingerstr. 5, 81679 Munich, Germany, office@cesifo.de)

2441 Marcelo Resende, Concentration and Market Size: Lower Bound Estimates for the Brazilian Industry, October 2008

2442 Giandomenico Piluso and Roberto Ricciuti, Fiscal Policy and the Banking System in Italy. Have Taxes, Public Spending and Banks been Procyclical in the Long-Run? October 2008

2443 Bruno S. Frey and Katja Rost, Do Rankings Reflect Research Quality?, October 2008

2444 Guglielmo Maria Caporale, Antoaneta Serguieva and Hao Wu, Financial Contagion: Evolutionary Optimisation of a Multinational Agent-Based Model, October 2008

2445 Valentina Bosetti, Carlo Carraro and Massimo Tavoni, Delayed Participation of Developing Countries to Climate Agreements: Should Action in the EU and US be Postponed?, October 2008

2446 Alexander Kovalenkov and Xavier Vives, Competitive Rational Expectations Equilibria without Apology, November 2008

2447 Thiess Buettner and Fédéric Holm-Hadulla, Cities in Fiscal Equalization, November 2008

2448 Harry H. Kelejian and Ingmar R. Prucha, Specification and Estimation of Spatial Autoregressive Models with Autoregressive and Heteroskedastic Disturbances, November 2008

2449 Jan Bouckaert, Hans Degryse and Thomas Provoost, Enhancing Market Power by Reducing Switching Costs, November 2008

2450 Frank Heinemann, Escaping from a Combination of Liquidity Trap and Credit Crunch, November 2008

2451 Dan Anderberg, Optimal Policy and the Risk Properties of Human Capital Reconsidered, November 2008

2452 Christian Keuschnigg and Evelyn Ribi, Outsourcing, Unemployment and Welfare Policy, November 2008

2453 Bernd Theilen, Market Competition and Lower Tier Incentives, November 2008

2454 Ondřej Schneider, Voting in the European Union - Central Europe's Lost Voice, November 2008

2455 Oliver Lorz and Gerald Willmann, Enlargement versus Deepening: The Trade-off Facing Economic Unions, November 2008 
2456 Alfons J. Weichenrieder and Helen Windischbauer, Thin-Capitalization Rules and Company Responses, Experience from German Legislation, November 2008

2457 Andreas Knabe and Steffen Rätzel, Scarring or Scaring? The Psychological Impact of Past Unemployment and Future Unemployment Risk, November 2008

2458 John Whalley and Sean Walsh, Bringing the Copenhagen Global Climate Change Negotiations to Conclusion, November 2008

2459 Daniel Mejía, The War on Illegal Drugs in Producer and Consumer Countries: A Simple Analytical Framework, November 2008

2460 Carola Frydman, Learning from the Past: Trends in Executive Compensation over the Twentieth Century, November 2008

2461 Wolfgang Ochel, The Political Economy of Two-tier Reforms of Employment Protection in Europe, November 2008

2462 Peter Egger and Doina Maria Radulescu, The Influence of Labor Taxes on the Migration of Skilled Workers, November 2008

2463 Oliver Falck, Stephan Heblich and Stefan Kipar, The Extension of Clusters: Differencein-Differences Evidence from the Bavarian State-Wide Cluster Policy, November 2008

2464 Lei Yang and Keith E. Maskus, Intellectual Property Rights, Technology Transfer and Exports in Developing Countries, November 2008

2465 Claudia M. Buch, The Great Risk Shift? Income Volatility in an International Perspective, November 2008

2466 Walter H. Fisher and Ben J. Heijdra, Growth and the Ageing Joneses, November 2008

2467 Louis Eeckhoudt, Harris Schlesinger and Ilia Tsetlin, Apportioning of Risks via Stochastic Dominance, November 2008

2468 Elin Halvorsen and Thor O. Thoresen, Parents' Desire to Make Equal Inter Vivos Transfers, November 2008

2469 Anna Montén and Marcel Thum, Ageing Municipalities, Gerontocracy and Fiscal Competition, November 2008

2470 Volker Meier and Matthias Wrede, Reducing the Excess Burden of Subsidizing the Stork: Joint Taxation, Individual Taxation, and Family Splitting, November 2008

2471 Gunther Schnabl and Christina Ziegler, Exchange Rate Regime and Wage Determination in Central and Eastern Europe, November 2008

2472 Kjell Erik Lommerud and Odd Rune Straume, Employment Protection versus Flexicurity: On Technology Adoption in Unionised Firms, November 2008 
2473 Lukas Menkhoff, High-Frequency Analysis of Foreign Exchange Interventions: What do we learn?, November 2008

2474 Steven Poelhekke and Frederick van der Ploeg, Growth, Foreign Direct Investment and Urban Concentrations: Unbundling Spatial Lags, November 2008

2475 Helge Berger and Volker Nitsch, Gotcha! A Profile of Smuggling in International Trade, November 2008

2476 Robert Dur and Joeri Sol, Social Interaction, Co-Worker Altruism, and Incentives, November 2008

2477 Gaëtan Nicodème, Corporate Income Tax and Economic Distortions, November 2008

2478 Martin Jacob, Rainer Niemann and Martin Weiss, The Rich Demystified - A Reply to Bach, Corneo, and Steiner (2008), November 2008

2479 Scott Alan Carson, Demographic, Residential, and Socioeconomic Effects on the Distribution of $19^{\text {th }}$ Century African-American Stature, November 2008

2480 Burkhard Heer and Andreas Irmen, Population, Pensions, and Endogenous Economic Growth, November 2008

2481 Thomas Aronsson and Erkki Koskela, Optimal Redistributive Taxation and Provision of Public Input Goods in an Economy with Outsourcing and Unemployment, December 2008

2482 Stanley L. Winer, George Tridimas and Walter Hettich, Social Welfare and Coercion in Public Finance, December 2008

2483 Bruno S. Frey and Benno Torgler, Politicians: Be Killed or Survive, December 2008

2484 Thiess Buettner, Nadine Riedel and Marco Runkel, Strategic Consolidation under Formula Apportionment, December 2008

2485 Irani Arraiz, David M. Drukker, Harry H. Kelejian and Ingmar R. Prucha, A Spatial Cliff-Ord-type Model with Heteroskedastic Innovations: Small and Large Sample Results, December 2008

2486 Oliver Falck, Michael Fritsch and Stephan Heblich, The Apple doesn't Fall far from the Tree: Location of Start-Ups Relative to Incumbents, December 2008

2487 Cary Deck and Harris Schlesinger, Exploring Higher-Order Risk Effects, December 2008

2488 Michael Kaganovich and Volker Meier, Social Security Systems, Human Capital, and Growth in a Small Open Economy, December 2008

2489 Mikael Elinder, Henrik Jordahl and Panu Poutvaara, Selfish and Prospective: Theory and Evidence of Pocketbook Voting, December 2008 
2490 Maarten Bosker and Harry Garretsen, Economic Geography and Economic Development in Sub-Saharan Africa, December 2008

2491 Urs Fischbacher and Simon Gächter, Social Preferences, Beliefs, and the Dynamics of Free Riding in Public Good Experiments, December 2008

2492 Michael Hoel, Bush Meets Hotelling: Effects of Improved Renewable Energy Technology on Greenhouse Gas Emissions, December 2008

2493 Christian Bruns and Oliver Himmler, It's the Media, Stupid - How Media Activity Shapes Public Spending, December 2008

2494 Andreas Knabe and Ronnie Schöb, Minimum Wages and their Alternatives: A Critical Assessment, December 2008

2495 Sascha O. Becker, Peter H. Egger, Maximilian von Ehrlich and Robert Fenge, Going NUTS: The Effect of EU Structural Funds on Regional Performance, December 2008

2496 Robert Dur, Gift Exchange in the Workplace: Money or Attention?, December 2008

2497 Scott Alan Carson, Nineteenth Century Black and White US Statures: The Primary Sources of Vitamin D and their Relationship with Height, December 2008

2498 Thomas Crossley and Mario Jametti, Pension Benefit Insurance and Pension Plan Portfolio Choice, December 2008

2499 Sebastian Hauptmeier, Ferdinand Mittermaier and Johannes Rincke Fiscal Competition over Taxes and Public Inputs: Theory and Evidence, December 2008

2500 Dirk Niepelt, Debt Maturity without Commitment, December 2008

2501 Andrew Clark, Andreas Knabe and Steffen Rätzel, Boon or Bane? Others' Unemployment, Well-being and Job Insecurity, December 2008

2502 Lukas Menkhoff, Rafael R. Rebitzky and Michael Schröder, Heterogeneity in Exchange Rate Expectations: Evidence on the Chartist-Fundamentalist Approach, December 2008

2503 Salvador Barrios, Harry Huizinga, Luc Laeven and Gaëtan Nicodème, International Taxation and Multinational Firm Location Decisions, December 2008

2504 Andreas Irmen, Cross-Country Income Differences and Technology Diffusion in a Competitive World, December 2008

2505 Wenan Fei, Claude Fluet and Harris Schlesinger, Uncertain Bequest Needs and LongTerm Insurance Contracts, December 2008 